\title{
CONTROLE E DISPUTA PELA DEMOCRACIA NA COMUNICAÇÃO SOCIAL
}

\author{
Eula D. T. Cabral \\ Adilson Cabral \\ Bruno Lima Rocha
}

\begin{abstract}
Resumo
Este artigo analisa o estado atual da mídia brasileira em relação à influência das empresas que constituem os meios de Comunicação no Brasil e a participação dos movimentos pela democratização do setor, buscando contribuir para o debate teórico e de perspectivas para uma melhor atuação por parte dos ativistas de comunicação comunitária, assim como do conjunto do movimento popular. Parte de uma pesquisa bibliográfica e documental, além da análise de dados recentes sobre o setor, que busca evidenciar a importância da constituição de políticas públicas democráticas para o favorecimento do empoderamento popular em nosso país.
\end{abstract}

Palavras-Chave: Políticas de Comunicação; Democratização da Comunicação; Mídia Brasileira; Empoderamento Popular; Radiodifusão Comunitária.

\begin{abstract}
This article analyzes the current state of the Brazilian media in relation to the influence of the companies that constitute Mass Communication Enterprises in Brazil . On the other hand, observes the participation of the movements for democratizing the media. The paper looks to contribute for the theoretical debate and of perspectives for a better performance on the part of the activists of communitarian communication, as well as the popular movement. The article goes through a bibliographical and documental research, besides the analysis of recent data, looking to evidence the importance of the constitution of democratic public politics for the people empowerment in our country.
\end{abstract}

Key-Words: Politics of Communication; Democratization of the Communication; Brazilian Media; Empowerment; Community Broadcasting.

\section{Panorama do ambiente da indústria da comunicação social no Brasil atual}

No século XXI, com a evolução das tecnologias e os processos de regionalização e globalização, verifica-se que a mídia se transformou num negócio rentável para a maioria dos empresários que passou a investir neste mercado em todos os lugares que proporcionassem lucro. Assim, com a desregulamentação, concentração e diversificação das atividades empresariais midiáticas, atuando também nos setores primário, secundário e terciário da economia, formaram-se grandes conglomerados 
de comunicação, incorporando os pequenos grupos. No Brasil, observa-se uma realidade interessante. A mídia brasileira é dominada por grupos familiares, políticos e igrejas que se fazem presentes, principalmente, nos veículos mais apreciados pela população brasileira: a televisão e o rádio.

Para além do que é visto e lido nos editoriais dos produtos da mídia corporativa, a política do controle das comunicações no Brasil atravessa uma luta de vida ou morte, propiciando uma mudança de modelo e de formas de luta. Isto implica uma análise correta, indo além de preceitos institucionais consagrados. Ou seja, a partir da análise estratégica da conjuntura vivida, busca-se apontar outras saídas para a afirmação da soberania popular e a construção de um novo espaço público, no que tange ao debate em torno do monopólio, do oligopólio e da propriedade cruzada, diante de um ambiente militante que vive a crise entre ser sociedade civil (carregando as implicações e contradições dessa filiação) ou recriar as formas para agir como movimento popular. Constituem agentes mais gravitantes deste sistema a Rede Globo, a estrutura orquestrada pelo Ministro das Comunicações (MiniCom) Hélio Costa ao final do primeiro mandato do Governo Lula e a aliança com a nova elite ocupante do Planalto neste primeiro momento de implementação da convergência e da digitalização das comunicações no país.

A legislação brasileira proíbe o monopólio e oligopólio da mídia, no artigo 220, parágrafo quinto da Constituição Brasileira (1988), além da participação societária do mesmo grupo em mais de cinco concessões em VHF (Very High Frequency) no país, e em duas em UHF (Ultra High Frequency) em cada Estado, de acordo com o Decreto 236/67. De acordo com verificação feita por Caparelli e Lima (2004), três grupos familiares nacionais (Rede Globo, Bandeirantes e SBT) estão em quase $100 \%$ do território brasileiro, algo considerado inadmissível pelas Leis do Brasil. E, no caso dos grupos regionais (Rede Brasil Sul-RBS, Organizações Jaime Câmara, Rede Amazônica de Rádio e Televisão, Grupo Zahran e Verdes Mares), estão dominando mais de $70 \%$ dos locais onde atuam e isso, em dados reais, significa que eles, mesmo 
negando, têm, também, grande influência política nos lugares - e isso é preocupante.

Não se deve ignorar que os grupos hoje estão, também, nas mãos de políticos e igrejas. Com o domínio de famílias, políticos e religiosos na mídia brasileira percebe-se que "os oligopólios se formaram através de uma brecha deixada na lei. Ela fixou os limites por entidade e por acionista, mas não previu um artifício simples: o registro de concessões em nome de vários membros da família" (LOBATO, 1995, p.36).

No caso da digitalização das comunicações, percebe-se que a disputa revive, na primeira década do século XXI, os embates da lei da difusão a cabo. Naquele momento, a maior emissora do país iniciou seu processo de endividamento sem fim. Processo este que, se não fosse por vultosas ajudas do Banco Nacional de Desenvolvimento Econômico e Social (BNDES) e de sucessivos governos da União, já teria levado essa empresa à falência, bem como o total das seis redes privadas nacionais, que compõem o oligopólio da comunicação no Brasil. Isto porque, como modelo de negócios, a teledifusão aberta no Brasil está quebrada. Todas elas, Rede Globo, Bandeirantes, SBT, Record, Rede TV e CNT não conseguiriam saldar nem $50 \%$ dos seus custos fixos, se não fosse pela publicidade oficial veiculada nas emissoras. Como negócio, a TV aberta depende diretamente de verbas públicas (RODRIGUES, 2005).

É na publicidade estatal, a mesma que é desviada em operações de lavagem e remessa ilegal de divisas (como as do Valerioduto, que consistiu no uso de dois bancos para entrada de dinheiro sem procedência), onde os conglomerados operando no país têm suas maiores fontes de receita. Como a prioridade das inserções de propaganda são para a TV aberta, as receitas do rádio vêm minguando muito em função disso. Do montante de publicidade pública e privada aplicada nas mídias, apenas $4 \%$ do total vai para o rádio, $56,1 \%$ deste vai para a TV, $21,5 \%$ para os jornais e $10,6 \%$ para revistas. Para as outras mídias, onde se inclui a eletrônica, o montante é de 6,9\% (GRUPO DE MÍDIA, 2004). 
Em recursos, a indústria da mídia movimenta em publicidade o total de R $\$ 5$ bilhões e 358 milhões de reais. Deste montante, mais da metade sai diretamente dos cofres públicos para propaganda de governo, institucional, e conforme provado na CPI dos Correios, ser devidamente desviado para caixas dois de campanha e outros investimentos. Dos gastos estatais com publicidade, mais da metade tem como destino os cofres da família Marinho e suas emissoras nos estados.

Além disso, na entrada do século XXI, na mesa de negociações entre governo federal, conglomerados de mídia e sociedade civil, os empresários de comunicação defenderam que a esperança para salvação de seus grupos dependia da aprovação da entrada do capital estrangeiro. No final de 2001, os representantes do Fórum Nacional pela Democratização da Comunicação (FNDC) se reuniram em Brasília defendendo que a entrada do capital estrangeiro ameaçava a submissão dos meios de formação de consciência nacional a perspectivas consideradas estranhas ao interesse público e a busca da afirmação da soberania popular, da democracia e da nacionalidade. Já para as lideranças da Associação Nacional de Jornais (ANJ), da Associação Brasileira de Emissoras de Rádio e Televisão (ABERT) e da Associação Nacional de Editores de Revistas (ANER), somente com a proposta aprovada o Brasil poderia se integrar no cenário mundial, com a mídia mais competitiva e continuando a ser responsáveis pela gestão e produção editorial das empresas.

O fato era que os grupos estavam perdendo o controle. A jornalista Giuliana Napolitano, na revista Poder, de fevereiro de 2002, verificou ainda que a dívida total das empresas estava superando a receita e o lucro líquidos. Caso do Grupo Estado com $\mathrm{R} \$ 436,3$ milhões, representando um nível de endividamento (sobre os ativos totais) de 70,8\%; do Grupo Abril com R\$ 1,4 bilhão, endividamento (sobre os ativos totais) de 97,1\%; e da Gazeta Mercantil de R\$452,3 milhões, levando à demissão de mais de 500 funcionários e a transferência do controle administrativo da empresa para o fundo WorldInvest. 
Observa-se que o modelo de oligopólio da mídia brasileira tem uma lógica de funcionamento baseada na usurpação de recursos e direitos, além da falta de gestão. Financiado com dinheiro público, o Estado que arrecada o botim impositivo também extrai da população o direito a ceder e retirar concessões que seriam públicas, mas de fato são apropriadas por elites dirigentes e lobbies político-técnicos que incidem na formulação de políticas públicas nos mais variados setores, chegando até a consolidar a ascensão e a queda de presidentes. Outro padrão de violência simbólica se dá na unificação nacional forçada a título de projeto de integração concebido e impulsionado durante a ditadura militar.

O modelo apresentado em escala nacional também se reproduz de forma idêntica nos estados, como na matriz do grupo RBS, controlado pela família Sirotsky há quatro gerações, grupo que atinge 99,7\% dos domicílios com televisão dos estados do Rio Grande do Sul e de Santa Catarina. A importância da presença dos captadores de recursos públicos e o livre trânsito pelos corredores do Planalto e do Ministério das Comunicações é algo evidente na contratação de intermediários influentes para altos cargos de gestão. No caso da RBS, pela presença de Pedro Parente, ex-ministro de Orçamento e Gestão e secretário de Fernando Henrique Cardoso, como vice-presidente executivo do grupo gaúcho. O exemplo ilustra o conceito: quando a situação é estrutural, mudam os atores individuais, mas as disputas e os interesses são os mesmos.

O chamado $4^{\circ}$ poder se funde com a classe política e os grandes grupos econômicos. É impossível diferenciar os campos de atuação e os interesses diretos entre políticos profissionais e donos de mídia. No Senado da República, um em cada três senadores são donos ou testasde-ferro de donos de grupos de comunicação. Já na Câmara, ao menos $26 \%$ dos parlamentares envolvidos na Subcomissão de Comunicação, dentro da Comissão de Ciência e Tecnologia, são radiodifusores. 40\% dos parlamentares estão na mesma situação (MATTOS, 2003).

De acordo com o levantamento feito pelo assessor do Partido dos Trabalhadores, Israel Bayma, em 2001, resultado do cruzamento de 33 
mil informações do Ministério das Comunicações, da Agência Nacional de Telecomunicações (Anatel) e do Tribunal Superior Eleitoral (TSE) no período de 1999 a 2001, cinco governadores de Estado e 47 dos 513 deputados federais eram oficialmente proprietários de emissoras de rádio e/ou TV. É o caso da família do ex-presidente José Sarney, proprietária da Rede Mirante de Comunicação, que tem, em nome de parentes, 39 concessões de rádios e TVs em cinco cidades do Maranhão.

Desde a Constituinte diversos grupos de interesses vinculados ao movimento popular e sindical vêm tentando se contrapor a este modelo. Nos debates verifica-se que nenhum modelo é tão concentrador como o brasileiro e mesmo os marcos regulatórios da Comunicação Social dos Estados Unidos são mais democráticos. Pela lei dos Estados Unidos, é inimaginável um telejornal atingir um pico de audiência de $70 \%$ ou $80 \%$, como é a média do Jornal Nacional (Rede Globo). Também é impensável a produção ser tão concentrada como no Brasil. Lá é prevista $70 \%$ de regionalização dos produtos de comunicação, enquanto aqui a média é inversa.

A Constituição de 1988 propõe no artigo 221 princípios para produção e programação das emissoras, evidenciando a "regionalização da produção cultural, artística e jornalística" (inciso III). A deputada Jandira Feghali (PC do B-RJ), em 1991, criou um Projeto de Lei que tem como foco a regionalização da mídia brasileira (CABRAL, 2006). Porém, somente em 2004 entrou em pauta no Congresso Nacional. E isso só aconteceu porque os conglomerados de mídia perceberam que essa é uma tendência do mercado brasileiro. Em 1999 o Anuário de Mídia 98/99 - Norte/Nordeste/Centro-Oeste (p.11) constatou que as regiões brasileiras "estão se desenvolvendo economicamente, evoluindo no perfil de compras, investindo na mídia e atraindo diversos setores da produção com oportunidades de negócio". Hoje observa-se o grande poderio dos grupos regionais no cenário nacional. A RBS, por exemplo, é o maior conglomerado regional do Brasil. Suas estratégias, conforme verificação feita por Paulo Scarduelli (1996), são os limites geográficos, os traços culturais e o tamanho de cada mercado. 
O grande trunfo das emissoras regionais, de acordo com as pesquisas da revista Meio e Mensagem, foi o investimento comercial dos anunciantes nas regiões: "Os mercados regionais passaram a ter peso importante na estratégia das empresas" (n. 830, 1998, p.52). Além disso, os "grupos regionais estão investindo em sinais via satélite para melhorar a qualidade da transmissão. A regionalização também desenvolve oportunidades de negócio muito interessantes" (n. 830, 1998, p.52). Para o superintendente comercial da Rede Globo de Televisão, Octávio Florisbal, "além de melhorar a cobertura regional, com o jornalismo local, por exemplo, a regionalização também desenvolve oportunidades de negócio muito interessantes. Pode-se gerar de US\$ 2 milhões a US\$3 milhões em mercados locais com pequenos anunciantes" (MEIO E MENSAGEM, n. 804, 1998).

Poucas e parciais estatísticas já são suficientes para a atestação de uma idéia-guia. Mantido este modelo concentrador das comunicações no Brasil, a democracia será delegativa, ritual, minimalista e representativa, sempre com níveis baixos de participação nas tomadas centrais de decisão.

\section{A arena atual: a digitalização e convergência dos meios}

A democracia no Brasil se encontra em plena encruzilhada. De um lado, o controle de nosso espaço público no oligopólio financiado pelo Estado de Direito. Do outro, um longo e largo caminho de soberania popular e democrática a ser construída. Para compreender o que está em jogo, cabe um breve recuo histórico, rumo ao ano de 1893. Neste momento, em paralelo a uma Guerra Civil no Rio Grande do Sul entre Chimangos e Maragatos, na cidade de São Paulo, um padre gaúcho avançava em seus experimentos com as ondas sonoras. Roberto Landell de Moura, nascido em Porto Alegre em 1861, antecipa-se ao italiano Guglielmo Marconi na descoberta e experiência da radiodifusão.

O Brasil de então afirmava sua aliança de classes dominantes numa república de fazendeiros, partidos estaduais e oligarcas. Sua majestade, o café, controlava os rumos da economia. Não havia política 
econômica além da exportação primária, e política industrial era algo inimaginável.

História muito parecida com a de outro brasileiro, homem genial que encantara o mundo com seus inventos. No dia 13 de setembro de 1906, Alberto Santos Dumont realizara seu primeiro vôo bem sucedido do protótipo 14 Bis. Altos mandatários da Inglaterra, França e dos Estados Unidos acompanhavam seus experimentos e testes há mais de uma década. De sua parte, o Estado brasileiro doa uma casa para o inventor, mas não criou nenhuma indústria aeronáutica nos seguintes 50 anos. Por ironia da história, na residência de Petrópolis, doada pelo Estado que o relegou, foi o local onde o aviador brasileiro se suicidou.

O mesmo se sucedeu em 1893, quando Landell de Moura transmitiu sinais e sons musicais por 8 quilômetros. Transmitiu da Avenida Paulista e o sinal alcançou o Alto de Santana. Os estudos comprovam que ele havia inventado o tríodo, ou seja, a válvula de três pólos. Com o invento, tornava-se possível modular uma corrente elétrica e transmiti-la, sem fios, a longas distâncias. Como prêmio, nem uma casa o Padre Roberto recebeu.

Os interesses nacionais e a política industrial a partir do invento foram mal como sempre. A primeira transmissão radiofônica oficial foi em 1922 e a pioneira emissora somente em 1923. Entre o invento de Roberto Landell de Moura e a inovação de Edgar Roquette Pinto com sua Rádio Sociedade, o país levou 30 anos. Porém, a invenção do gaúcho Roberto assim como a do mineiro Alberto, já havia sido usada por outros países. Potências da época, dentre elas a Inglaterra, por sinal, credora do Brasil, utilizaram estas invenções, tanto para o comércio e transporte, como para a guerra. Mas, o atraso do Estado em identificar objetivos estratégicos antes do benefício para as oligarquias é algo sistêmico. Com a digitalização, a tragédia ocorrida com Santos Dumont e Landell de Moura se repetem.

No Brasil da primeira década do século XXI, o pioneirismo e a capacidade de criação do $4^{\circ}$ setor nacional continuam firmes e com pouco ou nenhum suporte. O caminho brasileiro rumo à irreversível digitalização vem sendo marcado de lutas de gabinete, pressões de 
lobbies patronais de um lado e entidades nacionais representativas dos vários setores do movimento pela democracia na comunicação de outro. O braço científico desta luta, de inovação e auto-suficiência tecnológica, custou quase nada aos cofres públicos.

Ao longo de 10 meses do ano de 2005, 22 consórcios nacionais, envolvendo universidades, institutos, fundações e órgãos públicos de pesquisa tecnológica, desenvolveram as bases do Sistema Brasileiro de Televisão Digital (SBTVD). Nele trabalharam mais de 1.500 pesquisadores, que contaram com o investimento de $\mathrm{R} \$ 65$ milhões, dos quais $\mathrm{R} \$ 50$ milhões foram destinados às universidades componentes dos consórcios (cf. site da FINEP- Financiadora de Estudos e Projetoshttp://www.finep.gov.br). Ou seja, aos custos de R\$ 5 milhões por mês, $\mathrm{R} \$ 50.000$ reais por pesquisador e pouco menos de 2 milhões e meio por consórcio o Brasil atinge a capacidade de gerar seu próprio Sistema de TV Digital.

Isto significaria um trunfo nacional a ser comemorado como vitória na campanha do candidato da situação, assim como a autosuficiência em petróleo. Mas, a diferença com o combustível fóssil é que desta vez estes consórcios feriram os interesses dos produtores de imagens, bens simbólicos e identidades no Brasil. Por isso, o Ministro das Comunicações e representante destes interesses dentro dos altos mandos do Estado Nacional, parte para assinar o pré-acordo com os japoneses a partir de uma concepção acolhida na Casa Civil e no Palácio do Planalto. Tecnologia nacional, desenvolvimento técnico-científico em área sensível, domínio da cadeia dos semicondutores e até a capacidade de geração de ativos e produtos de exportação são colocados em segundo plano diante do interesse maior dos conglomerados de mídia e seus pares.

Quando se trata do sistema de rádio digital então, o problema se torna muito maior. Além de não contar com nenhuma pesquisa financiada, o ambiente é de abertura de fronteiras. O Ministério das Comunicações liberou, em setembro de 2005, uma licença provisória para algumas emissoras de rádio AM, operar de forma experimental um sistema americano que comporta o digital e o analógico. O problema 
não é esse, mas de custos, de ausência de regulamentação e falta de espaço nos dials do país. Não por coincidência, a licença já acabou e as cadeias de rádio, filiais do oligopólio, ampliaram os testes também para FM. Aplicam o sistema dos EUA, conhecido como IBOC (In Band on Channel). Apenas para ter uma idéia de custos e exclusão, neste padrão, os investimentos com estúdio e transmissão são da ordem de US\$ 75 mil. Para piorar os custos, ainda será necessário pagar royalties para a empresa estadunidense Ibiquity, detentora dos direitos do padrão ${ }^{1}$.

O problema está além do não-aproveitamento do SBTVD desenvolvido pelos consórcios técnico-científicos, que por sinal é adaptável para o rádio digital. Como a nova tecnologia não está regulamentada, ao lado do oligopólio se encontra outro agente de peso das telecomunicações, as operadoras de telefonia. Observando qual é o modus operandi das empresas do setor, realmente o respeito da regra formal é algo próximo do virtual.

Para os mais bem informados ou curiosos, basta acompanhar as operações do Banco Opportunity, de Daniel Dantas, Carla Cicco (Brasil Telecom) e a transnacional de investigações Kroll O'Gara (com filial em São Paulo e Curitiba). É um problema de fundo, num cenário onde o Estado refinancia aquilo que já privatizara e não contém nenhuma subida de tarifa. Sem a regulamentação prévia, estas transnacionais entrarão na mídia brasileira digital gerando conteúdo das mídias convergentes, abocanhando fatias enormes de mercado e desnacionalizando o mercado controlado pelo oligopólio.

Pouco a pouco, de forma lateral e sempre com matérias positivas e entusiasmadas, o público receptor da televisão aberta vai se acostumando a entender a TV digital e comemorar a alta definição. O problema não está aí, mas sim na exclusão de outras potencialidades. Dentre os padrões mundiais de digitalização, com certeza o país teria mais uma forma de competir gerando o nosso próprio padrão. Recursos para isso existem, tanto humanos como de investimento e podem ser

Cf. sites do Ministério das Comunicações (http://www.mc.gov.br) e Anatel (http://www.anatel.gov.br). 
verificados nas propagandas oficiais do governo da União ao longo da grade de programação das grandes redes.

Apenas para dar um exemplo de sua capacidade, o padrão brasileiro de TV Digital prevê dois conversores diferentes (cf. CPqDhttp:// sbtvd.cpqd.com.br). Um de baixo custo e outro de alta definição. Com este pequeno aparelho, que hoje com os investimentos necessários custaria em torno de $\mathrm{R} \$ 200$ reais, cada televisor se converteria em um receptor de sinal digital. $O$ padrão nacional também prevê um maior espectro, o que significa multicanalização. Ou seja, mais canais e possibilidades múltiplas de interação, transmissão, geração de identidades, regionalidades resgatadas, histórias re-escritas.

A pressão dos setores mais militantes da mídia popular, especificamente os que lutam pela democracia na comunicação, resulta na criação da Frente Nacional por um Sistema Democrático de Rádio e TV Digital. Esta Frente se caracteriza pelo perfil de sociedade civil organizada, somando múltiplos interesses, agentes, com base organizada, terceiro setor e um sem fim de atores individuais.

Fazendo volume no movimento, somam-se neste embate, quase 12 mil rádios comunitárias segundo os dados da própria Agência Nacional de Telecomunicações (Anatel). Seriam 2.464 processos abertos, dos quais 1.519 obtiveram a licença definitiva e 521 processos a licença provisória (dados consultados em março de 2006, referentes à totalização de 2005). Processos abertos com pedidos de cadastramento são mais 9.237. Pela estimativa da Associação Brasileira de Radiodifusão Comunitária (Abraço), as rádios comunitárias já ultrapassam 15 mil no país, somando-se os vários estágios de organização e legalização. Destas, o número de rádios organizadas de forma comunitária e com algum nível de engajamento não passa de $5 \%$ do total de emissoras.

No outro lado dos grupos de interesse estão os mais de 130 parlamentares na Frente da Radiodifusão, o poderoso lobby das duas associações patronais (ABERT e Abra- Associação Brasileira dos Radiodifusores), o próprio ministro Hélio Costa. Agindo por fora, os grandes operadores da telefonia transnacional, sob o manto jurídico do Telebrasil, do Sinditelebrasil e da Abrafixo. Ansiosamente aguardando 
uma ampla linha de crédito para produzir os receptores digitais estão os fabricantes (em sua maior parte apenas montadoras de componentes) instalados no Brasil. Estes, em sua maioria, organizam-se no guardachuva jurídico da Associação Nacional de Fabricantes de Produtos Eletroeletrônicos (Eletros).

Nesta disputa existem interesses estratégicos em jogo, tanto no plano nacional como de soberania popular. Entre a defesa dos oligopólios e os objetivos de longo prazo do país há uma infinita distância. Com a apropriação da tecnologia correta e com a cadeia produtiva sob controle nacional, será possível contar com o espaço público necessário para criar uma das novas bases da participação popular direta, a comunicação democrática.

\section{Montando as bases para fundamentar a análise}

As organizações da sociedade civil em geral ainda usam a comunicação de modo meramente instrumental, colocando-a à disposição de seus interesses institucionais, a despeito do crescente e bem-vindo interesse em relação à temática comunicacional, ao invés de tê-la como ferramenta para desenvolver atividades e perspectivas. Dessa forma abrem mão da capacidade de avaliar a implementação das suas frentes de luta e de fortalecer articulações entre atores afins. A comunicação pode contribuir bastante nesse sentido, se tida como um processo caracterizado pela construção de identidade de uma idéia, a produção de uma cultura que a consolide e a socialização do saber que a sustenta. Compreender esse processo é fundamental para localizar a importância dessa prática no cotidiano.

Para situar esta questão apenas em relação aos meios de circulação, que estão ao alcance da sociedade civil de um modo geral rádios comunitárias e canais comunitários de TV a Cabo -, os canais disponibilizados vêm sendo timidamente aproveitados e experimentados diante das possibilidades em relação às iniciativas implementadas, embora contenham um perfil novo de participação, basicamente formado por pessoas e grupos que perceberam a importância da formação de veículos próprios de comunicação, com uma dinâmica 
específica, seja para reforçar uma determinada comunidade, seja como alternativa de geração de renda ou de veiculação da produção.

Um desafio cada vez mais necessário é o de cativar comunidades e grupos de diferenciadas origens para a importância das experiências comunitárias implementadas, visto que se precisa levar em conta a adesão popular para fazer valer a própria existência das experiências de rádios comunitárias e canais comunitários de TV a Cabo, mostrando, nesse sentido, as peculiaridades que o modelo comunitário possui em relação à radiodifusão comercial. Cabe explicitar esta distinção dando ênfase às diferenças entre os dois modelos, às limitações impostas na linguagem e na rotina de trabalho pelos empresários de emissoras comerciais, que também veiculam inverdades em relação à interferência proporcionada pelo sinal das rádios comunitárias, além de afirmar e reforçar vantagens próprias das rádios comunitárias (proximidade, interatividade, etc.) no desenvolvimento de programas e da articulação da comunidade.

São decisões de definição simples, relacionadas ao projeto editorial, que fazem uma rádio afirmar seu perfil comunitário. Em primeiro lugar, sua própria concepção não é mais adequada à divulgação de sucessos das rádios comerciais. As pessoas capacitadas de uma determinada comunidade são ao mesmo tempo profissionais e formadoras, comunicadoras e educadoras, porque o ofício não é argumento de autoridade, mas sim um conhecimento a ser compartilhado com quem se interessar.

Por sua vez, as pessoas e grupos que participam da formação de canais comunitários em vários municípios, tendo o mérito de manter vivas suas experiências mediante restrições impostas pelo governo e pelas operadoras a cabo, perdem a oportunidade de formular discussões sobre outros pontos apresentados dentro da lei: tempo limite para cabeamento da área de concessão das operadoras, ocupação dos outros canais (além do comunitário), fundo de apoio à programação, etc. O espaço de encontro que a implementação dos canais comunitários possibilita pode servir como articulação para superar impasses econômicos e de programação, como também para formular novas 
perspectivas de legislação que levem a radicalizar a democratização desses espaços.

Além dessas contribuições, os processos de comunicação institucional passam pela construção de identidades comuns, que contemplem as contribuições específicas das entidades participantes de cada canal. Dessa forma, o interesse em veicular produções das entidades sem fins lucrativos seria aliado da necessidade de compartilhar ações, aproveitando a articulação proporcionada pelos canais comunitários.

A capacidade de refletir a definição das identidades, bem como suas afinidades e públicos comuns, não é devidamente estimulada no planejamento de veículos próprios, o que inviabiliza uma resposta mais elucidativa sobre o propósito de sua atuação. Mostrar as possibilidades de utilização dos veículos de comunicação comunitários diante da configuração do mercado (na condição de atividade-fim) e principalmente estimular a produção por parte das comunidades - até mesmo gerando iniciativas próprias, como as TVs Comunitárias dos anos 80 - se tornam necessidades cada vez maiores, na medida em que o cenário de uma sociedade produtiva vem se tornando uma nova realidade, independente das restrições legais ao desenvolvimento dos espaços de caráter comunitário. Tais iniciativas servem para aquecer e impulsionar a sociedade civil no âmbito das iniciativas já existentes, servindo como experiências para o dimensionamento de outras novas tecnologias, como a TV Digital ou as mídias digitais transmitidas pela Internet.

\section{Alguns conceitos aplicados para o debate público}

Uma das situações mais críticas para o movimento de comunicação é o pleito eleitoral. O governo de Luiz Inácio Lula da Silva contou com apoio de amplos setores do movimento acolhendo, em seu discurso de 2002, partes inteiras de um programa redigido pelo FNDC Fórum Nacional pela Democratização da Comunicação, a partir de suas entidades constitutivas, capitaneada pela Federação Nacional dos Jornalistas (FENAJ). Já em 2006, um coletivo de pessoas ligadas ao 
Governo Lula e a organizações do movimento pela democratização da comunicação lança um capítulo de comunicação incorporado ao Programa da Campanha de reeleição do Presidente Lula, trazendo itens não acionados no primeiro mandato e renovando a promessa de uma comunicação democrática acionada pelo aparelho de Estado.

Traduzindo para linguagem corrente, algumas ferramentas de análise e estratégia podem ser incorporadas como parte de uma formação básica para os militantes das bases do movimento pela democracia da comunicação, em especial dos ativistas de rádios comunitárias. A meta é pautar uma atuação que tenha em vista a ampliação dos direitos e realizações da democracia participativa, direta e deliberativa. Isto é, justo o oposto do regime de mando indireto, delegativo e de hiato de representação em que vivemos.

Assim, cabe elencar algumas frentes de atuação como elementos de discurso a pautar pessoas, grupos e organizações da sociedade civil na relação com os novos parlamentares eleitos e as conversações de governo:

- concessões públicas: os serviços são concedidos pelo público através do Estado. Outorgamos ao Estado a sua necessária regulação e este nos tira o direito à liberdade de expressão e comunicação. Um dos piores exemplos são as próprias concessões para canais de rádio e TV. Podemos inverter essa lógica criando Conselhos de Comunicação Social e Comunitária (em vários níveis: municipal, estadual e federal), com poder de deliberação e com a devida pressão popular. Isto implica, enquanto movimento popular, em desconstruir a idéia de que a Anatel e o MiniCom são legítimos como reguladores;

- política econômica: as fontes de receita e administração do Estado, a carga tributária, a aplicação do orçamento - como é o caso da muito aplicada e pouco discutida DRU, a Desvinculação dos Recursos da União - contingenciando verbas e canalizando-as para o esgoto da ciranda financeira. Dentro deste contingenciamento estão as verbas do Fundo de Universalização dos Serviços de Telecomunicação (Fust) e do Fundo para Desenvolvimento Tecnológico das Telecomunicações (Funtell), recursos que deveriam/poderiam ser usados pelas emissoras de difusão 
comunitária, mas nunca chegam. A luta pelo descontingenciamento e o devido uso dos fundos de acordo com as entidades de luta popular é uma pauta real e necessária;

- economia política: os modelos de serviços e negócios aplicados área por área e suas necessárias cadeias produtivas; tal é a situação da cadeia de semicondutores e de microeletrônica, especificamente na urgente necessidade de fabricação de chips no Brasil. Isto implica em ações simultâneas imediatas. Uma delas é a criação de centros de produção de ponta, como o Ceitec/RS cujo montante é irrisório para as verbas de governo ( $R \$ 160$ milhões para instalação física). Outra é a defesa do parque produtivo de Santa Rita do Sapucaí, MG, e os postos de trabalho da cadeia da eletrônica. E, por fim, alterar o modelo de negócios com verbas publicitárias públicas, financiando o monopólio e outras verbas, também públicas, financiando a expansão das teles;

- políticas públicas: as ações de governo para atender demandas da sociedade, universalizando o acesso a bens, serviços e oportunidades através de pesado investimento público; este é o caso emergencial da inclusão digital e do acesso a conteúdo e produção de informação. Isto implicaria em duas ações reivindicatórias simultâneas. Uma é o destino de $10 \%$ dos gastos com publicidade estatal para as emissoras comunitárias de rádio e TV (aberta e cabeada). Obviamente que a luta contra a repressão deve acompanhar o destino de verbas públicas. A outra é a inclusão digital, tanto através de pontos de acesso público, como pelo subsídio às empresas para facilitar a aquisição de computadores pela população;

- infra-estruturas necessárias: com a convergência digital dos meios, o país vai demandar uma ampliação de rede e suporte. Obviamente que as teles, cada vez mais organizadas a partir de fusões e também querendo gerar conteúdo, estão tentando entrar na fatia de mercado de Internet sem fio. Esta será a saída para ampliação da rede no Brasil e aumento do acesso público. Duas propostas confluem. Uma é a aplicação universal das antenas para internet Wi-fi (sem fio, via rádio), com raio de $100 \mathrm{~km}$. A outra, é o projeto da Rits de Redes Comunitárias de Internet sem fio. Os fundos do Fust e Funtel podem ser aplicados, e 
com as despesas por unidade familiar, sairiam hoje aos custos médios de $R \$ 15,00$ por lar. Ou seja, metade da tarifa básica de qualquer operadora.

Estes cinco conceitos e as respectivas informações correspondentes para sua execução no mundo real deveriam ser pauta da disputa. Este debate, assim como a matriz energética a ser aplicada em nosso desenvolvimento, a política externa do Brasil, o modelo agrícola e fundiário, dentre outros, seria informação estratégica para a maioria dos países. No caso do movimento pela democracia da comunicação, se somados alguns conceitos operacionais à pauta reivindicatória mais imediata, tem-se o surgimento de um projeto político para todo um setor, transversal ao movimento popular e à luta de classes no país.

O empoderamento passa pela capacidade de decidir nosso próprio destino, como classe e povo. Assim, para além das poucas variáveis de um destino pré-traçado pela disputa eleitoral, o conflito antagônico não se dá entre candidatos, mas entre forças sociais organizadas e as propostas de fundo estratégico para o país.

Eula Dantas Taveira Cabral é Doutora e Mestre em Comunicação Social pela Universidade Metodista de São Paulo (UMESP), professora e pesquisadora universitária, jornalista e editora do Informativo Eletrônico SETE PONTOS (www.comunicacao.pro.br/setepontos).

Email: euladtc@comunicacao.pro.br.

Adilson Vaz Cabral Filho é Doutor e Mestre em Comunicação pela UMESP e graduado em Comunicação Social pela UFF, (habilitação Publicidade e Propaganda), Professor do Curso de Comunicação da UFF, coordenador do EMERGE (Centro de Pesquisa e Produção em Comunicação e Emergência) e do Informativo Eletrônico SETE PONTOS.

Email: acabral@comunicacao.pro.br.

Bruno Lima Rocha é doutorando e Mestre em Ciência Política pela UFRGS, graduado em Comunicação Social pela UFRJ (habilitação Jornalismo), Coordenador do portal Estratégia e Análise (www.estrategiaeanalise.com.br) e pesquisador do EMERGE.

Email: blimarocha@via-rs.net. 


\section{Referências:}

BAYMA, Israel. Dados sobre a concentração da propriedade de meios de comunicação e o coronelismo eletrônico no Brasil. Brasília: Assessoria Técnica da Liderança do PT na Câmara dos Deputados, 2001 (mimeo).

BRASIL. Constituição da República Federativa do Brasil. São Paulo: Saraiva, 1988.

CABRAL, E. A regionalização da mídia brasileira. Unirevista, São Leopoldo, v.1, n. 3, p. 1-10, jul. 2006.

CAPARELLI, S.; LIMA, V. A. Comunicação e televisão: desafios da pósglobalização. São Paulo: Hacker, 2004.

GRUPO DE MÍDIA. Mídia dados, 2004. Disponível em: $<$ http://www.gm.org.br/midia dados/2004/index.asp $>$. Acesso em $12 / 03 / 2007$.

LOBATO, E. Raio $X$ das telecomunicações: oito grupos dominam as TVs no Brasil. Comunicação e Educação, São Paulo, ano 1, n. 3, p. 36-42, mai.-ago. 1995.

MATTOS, L. Donos de TV atuam em comissão na Câmara. 21 abr. 2003. Disponível em: <http://www.freelists.org/archives/radiolivre/042003/msg00049.html> Acesso em 13 jul. 2007.

MEIO \& MENSAGEM. ANUÁRIO DE MÍDIA 98/99Norte/Nordeste/Centro-Oeste. São Paulo:, 1999.

MEIO E MENSAGEM. Mercados regionais ganham impulso. Meio e Mensagem, São Paulo, v. 10, n. 804, 20 de abril de 1998.

MEIO E MENSAGEM. Na era da regionalização. Meio e Mensagem, São Paulo, v. 20, n. 830, 13 out. 1998.

NAPOLITANO, G. Será que eles virão? Poder online, fev. 2002. Disponível em: <http://www.poderonline.com.br/NR/exeres/003A65A434EF-4390-9872-CE3DE0951339.htm>. Acesso em: 25 jul. 2002.

RODRIGUES, F. Governo terceiriza gasto com publicidade. Folha de São Paulo, São Paulo, p. A6, 3 jan. 2005.

SCARDUELLI, P. Network de bombacha: os segredos da TV regional da RBS. 1996. 144 f. Dissertação (Mestrado em Comunicação Social), Escola de Comunicação e Artes, Universidade de São Paulo, [1996]. 